\title{
A CRISE ÉTICA DA RESPONSABILIDADE CIVIL: DESAFIOS E PERSPECTIVAS
}

\section{Alexandre Pereira Bonna ${ }^{1}$}

\section{Resumo}

Desenvolve um conceito para a responsabilidade civil. Reflete sobre os fundamentos filosóficos da responsabilidade civil a partir da teoria do direito natural de John Finnis, a qual é enraizada na tradição aristotélicatomista. Aprofunda a importância de uma dimensão ética na análise da responsabilidade civil. Demonstra de que modo os contornos da responsabilidade civil podem cooperar para a construção de uma comunidade mais ética. Problematiza sobre os fatores que contribuem para a atual crise ética da responsabilidade civil. Apresenta possíveis perspectivas para atenuar/abrandar essa crise.

Palavras-chave: responsabilidade civil; danos em massa; filosofia do direito; direito natural; crise ética.

\section{INTRODUÇÃO E APRESENTAÇÃO DA CRISE ÉTICA DA RESPONSABILIDADE CIVIL}

A responsabilidade civil é uma categoria jurídica que se ocupa em impedir e/ou remediar os danos, tanto o dano-evento (caracterizado pela violação de um dever na ordem jurídica) quanto o dano-prejuízo (calcado nas consequências danosas existenciais ou morais geradas pelo dano-evento). Assim, as leis e a Constituição, as decisões judiciais (inclusive as que aplicam a indenização punitiva), as políticas públicas e as práticas sociais em seu sentido amplo, na medida em que cuidem da distribuição dos encargos e direitos relativos aos danos existenciais ou materiais, visando a prevenção ou reparação/compensação dos mesmos, estar-se-á diante desse grande ramo do direito denominado responsabilidade civil.

Destarte, tendo como ponto de referência a tradição aristotélica-tomista refletida na teoria do direito natural revigorada de John Finnis nas obras Lei Natural e Direitos Naturais (2007) e Aquinas (2008), é possível conceber a categoria da responsabilidade civil como um poderoso instrumento ético do direito, na medida em que, seja prevenindo danos, seja reparando ou compensado-os, fortalece a promoção de diversos bens humanos básicos, assim como, no tocante à razoabilidade prática, prima pela realização do bem comum por meio do alcance da justiça distributiva ou comutativa.

Explica-se.

\footnotetext{
${ }^{1}$ Doutorando em Direito (UFPA).E-mail: alexandrebonna@yahoo.com.br
} 
O direito natural concebe o fenômeno jurídico a partir não apenas do plano institucional legislativo e jurisprudencial, mas também sob a ótica de uma dimensão ética, calcada na busca pela realização dos bens humanos básicos, que são valores que se relevam como razões para o agir humano de qualquer um, valores básicos estes que se forem respeitados ensejam a plena realização ou felicidade do ser humano (FINNIS, 2007, p. 30/36), chamada de eudaimonia por Aristóteles, felicitas por Tomas de Aquino e realização humana integral por John Finnis (2008, p. 85/86).

Nessa esteira, condutas individuais, políticas e arranjos voltados à realização desses bens básicos são virtuosos (éticos) enquanto as práticas que desmantelam, desrespeitam e despristigiam os bens humanos básicos são carentes de fundamentação ética por não ser razoável não perseguir os referidos bens inquestionáveis e autoevidentes, assim como por ferir frontalmente o princípio de que o bem dever ser feito (inclusive os bens humanos básicos) e o mal evitado (good is to be done and pursued, and bad avoided) (FINNIS, 2008, p. 80)

Portanto, ainda dentro dessa primeira aproximação da responsabilidade civil com o direito natural, percebe-se um vínculo umbilical entre o direito de danos e a ética na medida em que diversos danos perpetrados atingem bens humanos básicos, como por exemplo: a) as perturbações da saúde física e psíquica decorrentes de transtornos, irritações e acidentes atingem claramente o bem humano básico da vida; b) violações de direitos que acarretem alterações no projeto de vida, como descumprimentos contratuais relacionados a entregas de imóveis e mobília, fulminam o bem humano básico da razoabilidade prática no que diz respeito à sua exigência de que devemos possuir um plano coerente e racional de vida; c) moléstia de férias, momentos de lazer e descanço em geral podem ferir os bens humanos básicos do lúdico e da experiência estética; d) omissões de cunho informativo em contextos de compras de serviços e produtos ou negativa de acesso a banco de dados em qualquer âmbito podem gerar a transgressão do bem humano básico do conhecimento.

Nesse sentido, na medida em que as práticas jurídica e social dêem conta de promover e proteger os referidos bens humanos básicos no tocante aos danos, a responsabilidade civil estará cumprindo o seu papel ético. De outra via, caso o cenário da responsabilidade civil aponte para práticas sociais nocivas e danosas e para um Poder Judiciário incapaz de dar conta das funções de prevenção e/ou reparação/compensação dos referidos danos, aí estar-se-á diante de uma crise ética da responsabilidade civil, suntuosa do ponto de vista retórico e formal, mas precária e subdesenvolvida no plano fático-ético de perpetração de danos e constantes violências aos bens humanos básicos, o que ao fim e ao cabo leva à infelicidade humana tanto no aspecto individual quanto no comunitário.

Como se não bastasse, o aspecto ético da responsabilidade civil ainda se releva em outra fase do pensamento finnisiano: na busca pelo bem comum. Portanto, na passagem dos bens humanos básicos para juízos morais particulares e ações concretas, revela-se de suma importância o cumprimento das exigências da 
razoabilidade prática, dentre elas a busca pelo bem comum no sentido de que as questões individualizadas só possuem respaldo ético na medida em que promovem o bem de outros inseridos na referida comunidade comum (FINNIS, 2007, p. 143/144), portanto, o bem do outro passa a ser uma razão para agir e será consumado o bem comum na medida em que existir um "conjunto de condições que tendem a favorecer, facilitar e promover a realização, por parte de cada indivíduo, de seu desenvolvimento pessoal (...) seus próprios objetivos" (FINNIS, 2007, p. 148/157).

Desta feita, os membros de uma determinada comunidade devem conceber seus projetos individuais não apenas com o objetivo de concretizar os bens humanos básicos para si próprio, mas também como inseridos dentro de um contexto maior associativo no qual existe a união coordenada entre seres humanos, seja em grupos associativos menores como empresas, sindicatos, família, clubes e condomínios até em associações maiores como o próprio Estado. Nesse viés, o projeto individual exige sacrificios na medida em que o caso central (ideal) de associação é o sentido pleno de amizade de Aristóteles, exigindo-se que o bem (básico) do outro seja uma razão para o agir próprio, permitindo a realização integral de todos os participantes da referida prática, pequena ou complexa ${ }^{2}$.

Consequentemente, deve-se promover formas de organização e interpretação do direito que possibilite a realização do plano de vida de cada um dos participantes da prática social, cabendo ressaltar que sob a visão da tradição aristotélica-tomista, o ideal de uma comunidade virtuosa não pressupõe que o Estado é o único promotor do bem comum. Ao contrário, em cada grau da comunidade política (grupos associativos menores) subsiste o dever de os membros favorecerem o bem do outro, não havendo razões para o Estado promover esse bem comum quando o mesmo pode ser bem efetivado por grupos menores (princípio da subsidiariedade) (FINNIS, 2007, p. 146).

Por conseguinte, trazendo a ideia de bem comum para o seio da responsabilidade civil, sabe-se que a perpetração de danos representa não apenas a violação direta ou indireta de algum bem humano básico, como também o desrespeito à exigência do bem comum, tanto no aspecto associativo menor (relações de consumo, relações de trabalho, relações de família, relações contratuais em geral) como no maior (Estado), impedindo a construção de uma comunidade política mais ética e virtuosa, na medida em que um dano representa afronta à plena realização do outro, e, portanto, se caracteriza como uma violação ao dever de pautar o bem do outro como razão do agir próprio, contribuindo para a decadência dos fatores que fortalecem a colaboração mútua.

\footnotetext{
${ }^{2}$ É nesse sentido que Alasdair MacIntyre, ao questionar como é possível existir uma comunidade completa e virtuosa, responde que é preciso estar atendo para a virtude de práticas menores, motivo pelo qual formula três dimensões gradativas para se alcançar a comunidade plena e virtuosa: o alcance dos bens internos das práticas, o êxito na unidade narrativa da vida humana e, por fim, o respeito à tradição. Essas três etapas representam uma unidade conceitual da tradição da ética das virtudes (1981, p. 186) e devem ser compreendidas como estágios necessários para o alcance de uma vida virtuosa no mundo contemporâneo, com um pequeno cuidado: é condição fundamental para o êxito de um estágio o alcance prévio do estágio anterior. Assim, o terceiro estágio só atinge
} 
Na discussão jusnaturalista, um dos maiores instrumentos para a consecução do bem comum é a justiça (FINNIS, 2007, p. 161/163), categoria esta que só pode ser pensada de maneira interrelacional no sentido de que alguém deve algo a outrem, o que torna a ideia de justiça relevante para a reflexão da responsabilidade civil por ser este um típico instrumento que revela uma relação inter-relacional (ofensor-vítima) e pensar o que o ofensor ou potencial transgressor deve à vítima ou potencial vítima possui pertinência de justiça, afinal, o que é devido à vítima? E, dentro das espécies de justiça particular, tanto a justiça distributiva quanto a comutativa possuem desdobramentos na responsabilidade civil.

A justiça comutativa tem por objeto a reposição de perdas injustamente causadas no bojo da relação de indivíduo-indivíduo, indivíduo-grupo e/ou grupo-grupo (FINNIS, 2007, p. 176), e, nesse sentido, possui clarividente vínculo com a ideia de responsabilidade civil na medida em que a partir da perpetração do dano (evento ou prejuízo) no contexto de uma interação relacional mais simples (indivíduo-indivíduo, indivíduo-grupo e/ou grupo-grupo), é papel da responsabilidade civil indagar o que é devido a cada um.

De outro, lado, a justiça distributiva, entendida como o conjunto de exigências de colaboração que intensificam o bem-estar e as oportunidades de florescimento do ser humano (FINNIS, 2007, p. 165). A justiça distributiva parte do pressuposto de que não são todos os seres humanos que possuem as condições essenciais para o florescimento e atualização de suas potencias (realização de projetos de vida), motivo pelo qual para que se persiga o ideal de que todos alcancem a sua felicidade a partir da efetivação dos bens humanos básicos (como a vida, a sociabilidade, o jogo, conhecimento, experiência estética, dentre outros) deve haver - em uma sociedade extremamente desigual - uma efetiva colaboração das pessoas, sendo o papel da justiça distributiva coordenar o a distribuição de recursos, oportunidades, lucros, ônus, vantagens, papeis, responsabilidades, e encargos (FINNIS, 2007, p. 167/173).

A responsabilidade civil é sim um problema também de justiça distributiva, pois deve ser motivo de reflexão por parte dos juízes, advogados, defensores, legisladores e procuradores se ela não deve ser adequadamente dimensionada (políticas, direitos, deveres, condutas) para enfrentar violações constantes e graves de interesses juridicamente protegidos, possibilitando o fomento do bem comum e dos bens humanos básicos, inibindo/atuando em face da conduta causadora ou potencialmente causadora de dano.

Deste modo, a responsabilidade civil, no tocante à justiça comutativa (dar a cada um o que é seu), fomenta o respeito aos bens humanos básicos, prevenindo ou reparando/compensando os danos que atingem a esses bens, contudo, o alcance do bem individual atinge indiretamente o bem da comunidade. Na mesma linha, a responsabilidade civil, no tocante à justiça distributiva fomenta a realização dos bens humanos básicos na medida em que permite a compatibilização de projetos conflitantes em prol de um empreendimento comum, porém, o

sua plenitude se os estágios um e dois forem alcançados. (MACINTYRE, 1981, p. 181). 
alcance do bem comum atinge indiretamente os bens individuais por permitir a criação de um terreno fértil para condições e fatores de busca de bens individuais na complexa união comunitária.

Nesse ínterim, é preciso analisar se as práticas jurídicas e sociais estão não apenas satisfatórias em promover e proteger os bens humanos básicos individuais, mas também se as estruturas da responsabilidade civil possuem um esquema de distribuição de encargos, ônus e direitos satisfarórias para permitir o fortalecimento das condições e fatores que favorecem o alcance dos bens básicos por todos na esteira da justiça distributiva.

Contudo, em que pese a responsabilidade civil se revelar como forte instrumento para a construção de uma sociedade ética (virtuosa), surgem diversos obstáculos perceptíveis nas práticas sociais e jurídicas que tornam difícil o fortalecimento ético da comunidade a partir da responsabilidade civil, visto que muitas condutas danosas reiteradas perpetradas em larga escala não possuem como contrapartida uma resposta satisfatória do Poder Judiciário, seja em razão da morosidade, seja por que o valor indenizatório não é condizente com o mal causado, pois apenas uma parcela das vítimas busca a o Poder Judiciário. Como se não bastasse, não existem meios alternativos de solução de conflitos que suportem a dinâmica desses danos inseridos no seio de uma sociedade complexa e massificada, o que gera um campo perigoso no qual as interpretações que os próprios indivíduos e instituições possuem sobre os direitos prevalecem sobre a interpretação oficial, tornando possível conceber a existência de práticas danosas como parte normal de uma vida em sociedade atomizada e promotora de grande infelicidade.

Sendo assim, dentro da presente reflexão jusfilosófica da responsabilidade civil, indaga-se quais as razões que contribuem para a crise ética da responsabilidade civil e se revelam como desafios ao referido ideal ético?; quais as perspectivas para o futuro que podem contribuir para remediar essas razões? Na primeira parte da pesquisa serão arroladas e explicadas as seguintes razões/desafios: morosidade do judiciário; interpretação não autêntica e vagueza do direito; inefetividade de ações coletivas; profundo individualismo que ofusca a busca do bem do outro. Em tópico subsequente serão aprofundadas as seguintes perspectivas e projeções para abrandar/solucionar os desafios lançados à crise ética da responsabilidade civil: meios alternativos de solução de conflitos; fortalecimento de precedentes relacionados aos danos; punitive damages revigorado; sanções premiais.

\section{DESAFIOS: RAZÕES PARA A CRISE ÉTICA DA RESPONSABILIDADE CIVIL}

As razões para a crise ética da responsabilidade civil a seguir apresentadas não formam um rol exaustivo, nem tampouco foram desenvolvidas a partir de um critério metodológico rigoroso, uma vez que todos os tópicos abaixo representam percepções do autor a partir do olhar jusnaturalista - calcado na busca de realização dos bens humanos básicos - lançado ao fenômeno da responsabilidade civil no contexto de uma sociedade de danos. 


\section{Morosidade do Judiciário}

Sabe-se que o Direito desempenha uma função de ordenar a sociedade a partir da solução de conflitos calcados em pretensões opostas, o que desemboca, ao fim e ao cabo, no fomento da paz social e, em última instância, na realização dos bens humanos básicos, seja por meio da correção de injustiças no campo comutativo, seja criando padrões de conduta desejáveis tendo em vista a proteção do ser humano.

Contudo, para garantir o direito de acesso à justiça não é suficiente abrir as portas do judiciário permitindo o ajuizamento e processamento de ações judiciais, visto que é preciso declarar e efetivar o direito através da fase de conhecimento e execução em um tempo razoável ${ }^{3}$. Por conseguinte, o prolongamento indefinido de um processo judicial obstaculiza o acesso a direitos, faceta central na consecução da justiça e do bem comum, assim como acentua o estado de insegurança jurídica marcado pela incerteza sobre quem possui o direito, ofuscando inclusive o planejamento de ações e projetos de vida em face da indefinição causada pela morosidade.

Conforme levantamentos anuais realizados pelo CNJ nos dados do Relatório Justiça, a taxa média de congestionamento ${ }^{4}$ no primeiro grau é de $70,9 \%$, ou seja, a cada 100 demandas que foram ajuizadas, apenas 29 foram baixadas no mesmo período ${ }^{5}$, gerando um problema crônico de crescimento exponencial do congestionamento de processos junto ao Poder Judiciário, engendrando uma ameaça constante aos direitos não alcançados, aos projetos de vida não realizados, à justiça e ao bem comum, cada vez mais distantes em uma sociedade massificada que não possui um Judiciário à altura para sanear os conflitos sociais, falindo em sua missão institucional de pacificação de conflitos.

\section{Interpretação não autêntica no campo da indeterminação do direito}

Se há uma afirmação que se traduz como um estupendo consenso no campo da teoria do direito, é a de que a linguagem do direito muitas vezes é imprecisa e incapaz de em todos os casos estabelecer com precisão cirúrgica o direito a ser reconhecido, fenômeno esse chamado de vagueza da linguagem por Robert Alexy (2014, p, 123) - para justificar a necessidade de uma teoria discursiva racional -, de textura aberta por Herbert Hart (2007, p. 141) - para desenvolver o conceito de zona de penumbra e o preenchimento a partir da discricionariedade -, e de indeterminação por Hans Kelsen (1999, p. 245).

\footnotetext{
${ }^{3}$ A Emenda Constitucional n. 45/2004 introduziu o inciso LXXVIII no art. 5o da Constituição Federal de 1988: "LXXVIII - a todos, no âmbito judicial e administrativo, são assegurados a razoável duração do processo e os meios que garantam a celeridade de sua tramitação".

${ }^{4}$ A taxa de congestionamento mede a efetividade do tribunal em um período, levando-se em conta o total de casos novos que ingressaram, os casos baixados e o estoque pendente ao final do período anterior ao período base.
} 
Este último teório (Hans Kelsen) desenvolveu, no capítulo sobre interpretação jurídica da Teoria Pura do Direito (1999, p. 245/250), a diferenciação entre interpretação autêntica e não-autêntica. A primeira diz respeito à fixação do sentido do direito pelo Estado-juiz na solução de conflitos; a segunda àquela relizada por pessoas que não são órgãos jurisdicionais, uma vez que os indivíduos na vida em sociedade hão de buscar comportar-se conforme o direito, e, para isso, fazem escolhas não autênticas, correndo sempre o risco de estar agindo erroneamente.

A morosidade do judiciário na solução de conflitos aliada ao fato de que diversas vítimas de danos não buscam o Judiciário para satisfazer seus direitos - seja por desconhece-los seja pela apatia racional em razão da pequenez da indenização - faz com que impere no campo das relações jurídicas massificadas a interpretação do direito fornecida pelos setores jurídicos dos grandes litigantes, que se beneficiam da falta de efetividade da atuação jurisdicional para estabelecer o que é o direito sob sua ótica, agravando a crise ética da responsabilidade civil na medida em que vilipendia direta ou indiretamente os bens humanos básicos.

\section{Inefetividade das ações coletivas}

A construção do direito processual no Brasil e no mundo foi calcada em um tipo de perfil individual (Caio vs Tício) e não foi pensada para uma ótica de conflitos de massa. E, mesmo que no Brasil tenhamos o denominado microssistema de processo coletivo, formado pela Lei n. 4.717/1965 (Lei da Ação Popular), Lei n. 7.347/1985 (Lei da Ação Civil Pública) e Lei n. 8.078/1990 (Código de Defesa do Consumidor), o fato é que as ações coletivas não têm conseguido lidar com os conflitos de massa em razão da subsistência de ações individuais com a mesma questão de direito, assim como de conflitos de massa que albarrotam os setores de atendimento ao consumidor, as agências reguladoras, os procons etc.

Diversos motivos contribuem para a chamada ineficácia das ações coleitvas no Brasil, conforme elenca Fredie Didier e Leonardo Carneiro da Cunha (2016, p. 583/585):

a) não há uma quantidade suficiente de associações, de sorte que a maioria das ações coletivas tem sido proposta pelo Ministério Públicos ou pela Defensoria Pública, não conseguindo alcançar todas as situações massificadas que se apresentam a cada momento; b) há uma inadequada restrição de atuação das associações, como a exigência, por exemplo, de autorização expressa do indivíduo para se beneficiar da ação coletiva proposta pela associação; (...) d) o regime da coisa julgada coletiva contribui para que as questões repetitivas não sejam definitivamente solucionadas nas ações coletivas.

Desta feita, a lógica do processo civil voltada para a solução de conflitos individuais ${ }^{6}$ beneficia os grandes litigantes, que de atos com alto grau de censurabilidade, nocivos a uma massa de pessoas, recebem como

\footnotetext{
5 Fonte: http://www.cnj.jus.br/noticias/cnj/60538-numero-de-processos-baixados-cresce-93-em-cinco-anos-mas-nao-alcancademanda
} 
contrapartida do Judiciário indenizações fragmentadas calcadas em ações individuais. Como expus no meu "punitive damages (indenização punitiva) e os danos em massa" (2015, p. 8), esta lógica de responsabilização espraiada em demandas individuais de pequena parcela representativa das vítimas importa em um prêmio aos réus que praticaram condutas de alta gravidade, já que o preço para um padrão ótimo de suas atividades é inferior aos valores indenizatórios arbitrados judicialmente. Por consequência, quem arca com o prejuízo não suportado pelo ofensor é a sociedade (MCGOVERN, 2010, p. 452/453).

A permanência de uma lógica de resolver danos de massa de maneira individualizada contribui para que o ilícito seja vantajoso do ponto de vista econômico e, na mesma proporção, fornece conseguências nocivas para a violação constante e em larga escala de bens humanos básicos, realidade que revela que as escolhas no campo privado "são debatidas num contexto de custo e benefício" (Tradução Livre) (SEBOK, 2007, p. 166).

A falência das ações coletivas cria um campo fértil para que os grandes litigantes possam saber previamente o percental de vítimas que adentraram em juízo e quanto deverão desembolsar por essas indenizações, vislumbrando a vantagem econômica de lesar o direito de outrem.

\section{Individualismo}

A modernidade descrita por Alasdair MacIntyre (1981) se revela como um espaço no qual as pessoas encontram-se separadas de seus papeis sociais com a perda da noção de dependência na vida do outro e na comunidade como um todo. $\mathrm{O}$ indivíduo liberal moderno é desprovido de um telos comunitário, visto que a modernidade produziu a ideia de ser humano destacado de seus papeis sociais, o que não havia nas sociedades pré-modernas, onde o sujeito extraia seus deveres e obrigações a partir da sua relação com os diversos grupos sociais, visto que o próprio espaço particular do indivíduo só fazia sentido se estivesse em harmonia com as suas relações sociais (MACINTYRE, 1981, p. 33).

No campo das relações privadas promotora de danos em larga escala esse individualismo fica ainda mais evidente quando se relembra que as decisões do empregador e/ou fornecedor de produtos ou serviços são tomadas na ótica do custo-benefício (um bem externo à prática social, que só beneficia uma das partes).

$\mathrm{Na}$ medida em que se perde o elo com o vínculo comunitário, se enfraquece a adoção de condutas direcionadas ao bem da comunidade ou ao bem do outro, tornando a referida prática deficitária no alcance dos bens humanos básicos, porque um dos elementos propulsores que devem estar presentes em cada ato para a relização plena do ser humano é o alcance do bem comunitário, ideal esse ofuscado pelo profundo individualismo das sociedades atuais.

\footnotetext{
${ }^{6}$ Cabe ressaltar que o art. 333 do Novo Código de Processo Civil (Lei n. 13.105/2015), que permitiria a conversão de ação individual em coletiva, foi vetado.
} 
Contudo, aqui cabe destacar a precisa observação de Luis Fernando Barzotto (2017), segundo o qual, mesmo o mercado sendo caracterizado por participantes com interesses contrapostos (consumidor-fornecedor), é possível identificar a relização do bem da amizade, do tipo utilidade e centrada na troca:

Para o jusnaturalismo clássico (Aristóteles) e moderno (Smith), a troca tem seu fundamento na natureza humana. Para a satisfação mútua de necessidades, os seres humanos devem entrar em relações colaborativas. Se os seres humanos não precisassem uns dos outros, não trocariam ou o que é o mesmo, não estabeleceriam nenhuma relação entre si.

Luis Fernando Barzotto (2017) reconhece claramente a desvantagem da amizade mercantil por ela não possuir o sentido pleno de amizade (pautar como razão do agir o bem do outro), contudo isso não afasta a constatação de que o livre mercado permite o fomento de um tipo de amizade, e, portando possibilita a atualização da natureza do ser humano a partir de algo que integra a sua felicidade, afinal o ser humano é naturalmente inclinado para a convivência. $O$ mercado, então, ao menos evita que o ser humano se embrutece em seus próprios interesses, sendo "uma relação intrinsecamente moral, podendo ser pensada a partir da categoria da "amizade" tal como proposta por Aristóteles" (BARZOTTO, 2017)

Contudo, em que pese a grande contribuição de Luis Fernando Barzotto, ao identificar um liame entre as características do mercado descritas por Adam Smith e o conceito de amizade construído por Aristóteles, isso não afasta o fato de as relações jurídicas de massa serem vilipendiadoras de diversos bens humanos básicos, especialmente naquelas onde há um monopólio na realização de determinada atividade ou mesmo um grande hiato econômico entre as partes, acendendo o alerta para constantes violações de direitos de pessoas vulneráveis. Assim, em tendo o ser humano bondade limitada e um sério compromisso em promover o seu próprio bem desvinculado do bem do outro, faz-se necessária reflexão jusfilosófica para a decadência dos bens humanos básicos inseridos na lógica do consumo e do trabalho em massa.

\section{PERSPECTIVAS: PROJEÇÕES FUTURAS PARA ABRANDAR A CRISE ÉTICA}

\section{Meios alternativos de solução de conflito}

Como resposta à morosidade do judiciário e inefetividade das ações coletivas, impõem-se um repensar em alternativas ao modo tradicional de solução de conflitos centrado no Poder Judiciário, o qual vem dando sinais de falência no cumprimento de sua missão institucional de pacificação. Consequentemente, deve o Estado buscar diminuir as tensões e aumentar a harmonia social.

É claro que nosso ordenamento jurídico se encontra bem servido de regulamentação da mediação, conciliação e arbitragem, contudo, tais mecanismos alternativos à jurisdição não têm galgado êxito e o Poder Judiciário alberga um crescimento exponencial de processos. Portanto, é preciso fomentar uma cultura de acordos através de políticas de incentivo; reformular a legislação sobre o tema, de modo a impor multas àquele que se 
negar a realizar um acordo em bases semelhantes às fixadas em sentença, tal como fez a Inglaterra no Civil Procedure Rules; investir na qualificação de conciliadores e mediadores e nos centros de conciliação dos tribunais.

\section{Fortalecimento de precedentes obrigatórios}

Como resposta ao problema do monopólio da interpretação não autêntica por parte dos grandes litigantes, impedindo que os mesmos ditem o direito das grandes massas de trabalhadores/consumidores e até mesmo de contribuintes - no caso da Fazenda Pública - tem-se o fortalecimento do sistema de precedentes obrigatírios.

O precedente é uma decisão judicial extraída a partir do litígio que tem potencial de servir como parâmetro para outros casos idênticos ou análogos, permitindo que casos semelhantes tenham soluções semelhantes. No Brasil, tem-se dois tipos de precedentes: o persuasivo e o obrigatório. O primeiro possui uma força meramente argumentativa e pode ou não ser incorporado na fundamentação de decisões judiciais em casos futuros; o segundo, que pode ser uma das decisões que constam no rol do art. 927 do Código de Processo Civil (Lei n. 13.105/2015), possuem a sua ratio decidendi (ou holding, ou fundamentos determinantes da decisão) como de observância obrigatória perante o tribunal que o criou e demais tribunais e órgãos jurisdicionais hierarquicamente inferiores.

Na proporção em que as hipóteses de violações de direitos no campo dos danos materiais e morais constarem com maior frequência em precedentes obrigatórios, menor será o espectro da interpretação não autêntica, principalmente se for considerado que o pedido na fase de conhecimento que estiver em harmonia com um precedente obrigatório permite a concessão da tutela de evidência (art. 311), assim como o pedido recursal em consonância com precedente obrigatório gera provimento monocrático do referido recurso (art. 932, V), tornando cada vez mais inútil a manutenção de práticas violadoras de direitos já devidamente reconhecidas como tal pela direito oficial do Estado-juiz?

\section{Punitive damages revigorado}

Como resposta ao individualismo e ao profundo desinteresse em pautar o bem do outro (dos

\footnotetext{
${ }^{7}$ Cabe ressaltar que o peso obrigatório de precedentes não viola a legalidade nem tampouco a democracia, visto que os tribunais, ao edificarem precedentes obrigatórios, tem como ponto de partida a Constituição e as leis, motivo pelo qual um dos elementos integrantes de qualquer precedente é a argumentação jurídica. Portanto, o que vincula do precedente é a solução dada ao caso a partir do direito institucionalizado/legislado. É esse caminho, chamado de norma jurídica geral (pois se desprende do caso dos autos para servir de parâmetro a outros casos) que vincula, sendo errônea a afirmação que os precedentes vinculantes fomentam a atividade criativa do judiciário. Ao contrário, o respeito aos precedentes obrigatórios fomenta e dissemina o respeito, em última análise, do próprio direito legislado. Pode-se concluir que os juízes e tribunais participam da atividade de criação do direito, mas em
} 
consumidores, trabalhadores, contribuintes), surge a premente necessidade de revigorar a teoria dos punitive damages (indenização punitiva) no direito brasileiro, teoria essa que esse encontra atualmente maltratada, mal aplicada, vilipendiada, esquecida, ignorada, mal compreendida. É preciso, de uma vez por todas, robustecer a aplicação dos punitive damages (indenização punitiva) no Brasil em face de atos de alto grau de censurabilidade, permitindo o desestímulo de condutas indesejáveis ao mesmo tempo em que preveni danos que mancham os bens humanos básicos e assolam os projetos de vida, em última instância, a felicidade das pessoas ou até mesmo de uma sociedade inteira, como no caso dos danos sociais desenvolvidos por Antônio Junqueira de Azevedo (2004), que geram um rebaixamento da qualidade de vida de toda uma comunidade.

Caminha-se em rotas tortuosas sempre que se discute a teoria dos punitive damages (indenização punitiva) no Brasil, visto que as principais pesquisas já produzidas sobre o tema não investigaram a fundamentação ética do instituto, limitando-se a desbravar o cabimento ou não dos punitive damages no ordenamento jurídico brasileiro sob o prisma dogmático. Destacam-se o meu livro (2015) e o do Cristiano Chaves de Farias, Felipe Peixoto Braga Netto e Nelson Rosenvald (2015), as teses de Ricardo Pedro e Serpa (2011), Geandrei Stefanelli Germano (2011), Marcela Alcazas Bassan (2009), André Gustavo de Andrade (2009), Carolina Vaz (2009), a obra de Maria Celina Bodin de Moraes (2009) e o artigo de Judith Martins-Costa e Mariana Pargendler (2005).

Os punitive damages se caracterizam como uma verba indenizatória que possui um objetivo bem específico: impor um valor indenizatório maior do que o suficiente para compensar ou reparar o prejuízo causado de modo a fomentar a dissuasão/prevenção/detenção de uma conduta com alto grau de censurabilidade. Não se pode ouvidar que esse instituto é bem versátil e ao lado do maior objetivo (desestimular o ofensor) acaba desempenhando muitos outros, como função general deterrence (desestímulo de outros potenciais infratores na sociedade), retribution (castigo), education (educação), compensation (compensação) e law enforcement (cumprimento da lei) ou public justice (justiça pública) ${ }^{8}$, funções essas que não serão aprofundadas nessa oportunidade.

Apesar de nas relações privadas aparentemente os participantes busquem os seus próprios interesses, não se pode negar que é possível estabelecer um conjunto de valores e bens que se forem alcançados beneficiam todos os participantes e formam um terreno fértil para a concretização das excelências humanas através do exercício das virtudes. Portanto, é possível buscar um bem comum inerente à prática e ao grupo, recuperando o interesse pelo aspecto comunitário e social e é justamente nesse aspecto que o Direito, por intermédio por exemplo dos punitive

graus distintos. Enquanto que os legisladores criam as bases primeiras do que é o direito, os juízes e tribunais constroem as formas de aplicação desse direito legislado à multifacetada e complexa vida humana.

${ }^{8}$ Classificação feita por Jim Gash (2005) em estudo denominado "Solving the multiple punishments problem: a call for a national punitive damages registry". 
damages, pode impor um padrão de conduta desejável.

Deste modo, mesmo que seja uma realidade o alto nível de desinteresse pelo outro no bojo das práticas sociais, notadamente as de consumo e de trabalho, onde os participantes tendem a buscar seus próprios interesses ao invés do bem do grupo, não se deve perder de vista que conceder um alto peso à liberdades e escolhas individuais pode representar uma grave disordem no plano social, pois quanto mais fraco são os laços de dependência dentro de um grupo mais distante fica o ideal de cooperação em prol de um objetivo comum.

Ora, mas o que tudo isso e o problema introduzido tem a ver com a justiça e com o bem comum de uma dada comunidade? A justiça é uma das exigências da razoabilidade prática, que é um dos bens humanos básicos e tem por objeto a realização do bem comum. Desse modo, a justiça está relacionada à colaboração em conjunto em relação a certos valores na esteira de uma reciprocidade, reconhecendo o que é devido a outrem como um direito de outrem e um dever seu e inviabilizando escolhas arbitrárias para os projetos de vida. Quanto mais justas forem as relações dos membros, mais fértil é o terreno para o alcance de bens internos, gerando uma onda de benefício para todos os participantes e assegurando maiores condições para a consecução dos projetos particulares de cada um.

É por esse motivo que o objetivo do Direito, dentro de uma concepção jusnaturalista, é compreender quais são os bens humanos básicos (vida, conhecimento, jogo, experiência, estética, sociabilidade, razoabilidade prática, religião) que indicam as formas básicas de florescimento, sendo possível, a partir dos critérios da razoabilidade prática (um plano de vida coerente, sem preferência arbitrária por valores, sem preferência arbitrária por pessoas, desprendimento, compromisso, a relevância limitada das consequências, respeito por cada valor básico em cada ato, exigências do bem comum, seguir a consciência) "distinguir entre atos que são razoáveis levando-se tudo em consideração e atos que são desarrazoados" (FINNIS, 2007, p. 30/36).

De todos os requisitos da razoabilidade prática, o mais pertinente com a presente pesquisa é o bem comum, ou melhor, aquilo que é exigido pelo mesmo. Em uma compreensão bem ampla, ele está relacionado com o pautar como razão para o agir o bem do outro (FINNIS, 2007, p. 143/144), que envolve, dentre outras coisas, garantir um "conjunto de condições que tendem a favorecer, facilitar e promover a realização, por parte de cada indivíduo, de seu desenvolvimento pessoal (...) para que cada um dos membros atinge seus próprios objetivos" (FINNIS, 2007, p. 148/157).

Quando se volta para a envergadura social de alguns danos perpetrados no bojo das relações privadas de massa, se percebe que a fraqueza do Direito para detê-las ofusca a possibilidade de alcançar uma comunidade plenamente realizada e completa do ponto de vista ético, pois o bem comum relativo à prática das relações privadas não estará sendo alcançado, o que causa muitas vezes o rebaixamento da qualidade de vida dos participantes. 
Nesse desiderato, se é possível refletir o direito a partir de bens humanos básicos, é possível então julgar decisões, leis e práticas sociais à luz da obediência ou não a tais bens, pois do contrário serão consideradas deficitárias quanto ao caso central. Assim, o jusnaturalismo exige que os bens humanos básicos sejam superiores às instituições, leis, decisões e práticas, o que se caracteriza como uma exigência muito mais abrangente e forte de determinados padrões de conduta de envolvidas em práticas e instituições, sendo possível fazer severas críticas sobre o uso da autonomia privada e da propriedade privada no contexto das relações de trabalho e de consumo, visto que se esse sistema privado não estiver promovendo o bem comum não estará satisfazendo uma exigência de justiça e, portanto, mesmo que a Lei Positiva esteja inteiramente sendo cumprida, a referida prática será injusta.

O raciocínio jusnaturalista não é antagônico a Lei Positiva, ao contrário, busca em grande intensidade reafirmar, fortalecer e solidificar o que aquela propunha (FINNIS, 2015, p. 1). Além disso, o que o jusnaturalismo propõe é compreender que a Lei Positiva é apenas uma das facetas fundamentais do direito e que não pode existir dissociada, independente e alheia a qualquer valoração de cunho ético relativa aos bens humanos que devem ser perseguidos. Ao contrário, o Direito pode e deve ser fundamentado também como uma boa razão para a ação no plano ético, visto que um conjunto de normas legisladas ou de precedentes judiciais não podem por si só serem considerados uma boa razão para a ação, como destaca Carlos Massini-Correas, comentando o pensamento de John Finnis:

(... ) ningún hecho o conjunto de hechos, por muy complejo que sea, puede proporcionar por sí mismo una razón para actuar ( ... en la medida en que se enorgullece de ocuparse sólo de hechos, no puede ofrecer una comprensión adecuada, ni de las razones para la acción (los deberes), ni de la única fuente concebible de estos deberes, es decir, los verdaderos e intrínsecos valores (2015, p. 43/44)

Portanto, o jusnaturalismo não nega a validade do Direito no plano institucional e social-fática, apenas compreende que essa é apenas uma dimensão de validade para uma visão completa do Direito, que debe ser visto também sob o plano ético, porém ambas as dimensões integram o que se pode denominar de Direito (MASSINICORREAS, 2015, p. 31). Ratifica-se, o que é considerado natural no jusnaturalismo é o que estive rem harmonia com os requisitos da razoabilidade prática, que envolve, dentre outras exigencias, o respeito ao bem comum. Por esas e outras razões, o jusnaturalismo já foi malinterpretado por aqueles que pensam que o mesmo persegue a natureza como algo relacionado aquilo que é inerente à vida humana ou a impulsos naturais, negligenciando que o jusnaturalismo é um apelo à razão.

Em meu livro (2015, p. 148/151), após inventariar um sem número de decisões judiciais no Brasil que aplicaram os punitive damages (indenização punitiva) identifiquei as seguintes fragilidades e debilidades na experiência brasileira no tocante à indenização punitiva, o que gera uma falência no escopo de prevenir danos e promover o desestímulo de condutas danosas. 
Infere-se a compatibilidade dos punitive damages com os fundamentos éticos jusnaturalistas na medida em que os mesmos visam a brecar condutas com alto grau de danosidade e censurabilidade, por danos físicos ou econômicos, alto grau de desinteresse pela vítima, reiteração e muitas vezes se caracterizam pela tentativa de se beneficiar da vulnerabilidade do outro. Por essas e outras, as práticas combatidas pelos punitive damages são contrárias ao direito por serem antagônicas às exigências do bem comum e negligenciarem o ideal de respeitar os aspectos básicos dos membros de uma dada comunidade.

Deste modo, o Poder Judiciário deve se imbuído de razões de cunho ético para limitar o campo de atuação da autonomia, tendo sempre em vista uma concepção de bem comum que favoreça o florescimento humano, sendo necessário para isso, em casos mais graves, impor uma indenização maior do que a suficiente para compensar ou reparar o prejuízo, de modo a desestimular a conduta do ofensor que esteja desatinada com o bem comum da sociedade que o cerca. Deve-se, portanto, compreender o compromisso do Direito com a detenção e desestímulo de condutas indesejáveis, pressupondo que a investigação racional para determinar o que é o direito não abre mão da investigação do que o bem comum exige em um dado contexto, exigência esta que se torna parte do direito e da noção do que é justo no particular.

Nesse viés, o problema da justiça exige preocupação com a maneira mais adequada de tratar o outro, de modo a preservar uma razoável relação entre as pessoas, o que exige certamente o dever de evitar a prática de atos danosos, assim como o dever de suportar a punições pelas infrações cometidas (FINNIS, 2008, p. 188). Assim, aquelas condutas mais graves no âmago das relações privadas devem ser eliminadas a partir do manejo do valor indenizatório com o fim de neutralizar a subsistência de relações e práticas injustas, como destaca John Finnis à luz do pensamento de Tomás de Aquino sobre o direito de danos:

Aquinas sees 'recompense' or 'compensation' in Aquinas' thought this 'cure' involves far more than the possible reform of the offender, and includes also the restraining and the sheer deterrence of the offender and of everyone else who needs deterring from wrongdoing and coercive inducement to decent conduct. and of everyone else who needs deterring from wrongdoing and coercive inducement to decent conduct (...) this (re)ordering \{ordinativa\} point of punishment can either be accounted remedial \{medicinalis\}, or contrasted with the remedial (deterrent, reformative) $(2008,211 / 212)$.

Cabe salientar que não se está a defender o cabimento de indenizações milionárias que inviabilizem a iniciativa privada, visto que alguns dos requisitos para que os punitive damages guardem harmonia com a fundamentação ética é que o ato em análise seja muito grave, o valor das indenizações punitivas sejam proporcionais ao mal causado e ao objetivo de desestimular o ofensor, ideias estas que guardam relação com o objetivo de perquirir o bem comum presentes no pensamento de Tomás de Aquino exposto por John Finnis (2008, 211/212): "punishment, though merited, need not be imposed when its imposition would cause disproportionate harm to others; punishment is a matter of fairness and the measure of that fairness is the common good for the whole community." 
Expliquei (2015, p. 148/151) que a indenização punitiva no Brasil não é capaz de gerar desestímulo porque a) é marcada também por ausência de fundamentação quanto à gravidade da conduta que descambou na punição; b) falta de distinção entre valores relativos à compensação do dano moral e os destinados à punição e dissuasão; c) decisões judiciais apenas elevam o valor da indenização compensatória aludindo a indenização punitiva, mas não discriminam qual o valor suficiente para fazer frente ao prejuízo e qual se presta para punir e prevenir a conduta; d) no campo processual, a prática da indenização punitiva no Brasil em face de danos reiterados em larga escala aponta para uma visão essencialmente individual do referido instituto com fraca repercussão econômica do valor indenizatório em face do ofensor, afastando a possibilidade de uma proporção razoável entre a punição e o mal causado, por se tratar de demanda onde parcela expressiva das vítimas está ausente; e) há grandes fornecedores de produtos ou serviços, que de forma reiterada perpetram ilegalidades em larga escala, mas em contrapartida tem como resposta da função punitivo-dissuasória desconexas e fragmentadas com a gravidade dos danos, com os lucros obtidos com o ilícito, com o grau de censurabilidade da conduta, etecetera.

Desse modo, os punitive damages podem romper com a iníqua equação pautada pelo resultado de uma relação custo/benefício do seu comportamento em detrimento dos direitos dos consumidores, trabalhadores e de todas as vítimas inseridas no contexto dos danos em massa, impedindo o ofensor de se beneficiar ou lucrar com o dano causado ou de encontrar na sanção meramente compensatória um preço conveniente, o que impede, ao fim e ao cabo, uma postura individualista e desinteressada no bem do outro, permitindo o zelo pelos bens humanos básicos do ser humano e por vezes da qualidade de vida de toda uma comunidade.

\section{Sanções premiais}

Também como resposta ao individualismo, vislumbra-se como perspectiva o incremento de sanções premiais como forma de fomentar boas práticas no campo das relações jurídicas de massa e privadas. Cabe ressaltar que Herbert Hart (2010, p. 209), ao analisar a necessidade de regras primárias coercitivas mínimas no sistema jurídico para assegurar a viabilidade de vida comunitária, aduz que caso as mesmas não existam não se pode esperar que o ser humano tomará a iniciativa de comportar-se harmonicamente com os outros ou que fará o bem ao outro, como por exemplo pagar $13^{\circ}$ salário, conceder férias, trocar produtos viciados, devolver dinheiro recebido indevidamente, requisitos mínimos de qualidade de serviços realizados em regime de monopólio como concessionárias de energia elétrica e de transporte público, proibições mínimas de práticas comerciais no âmbito do direito do consumidor e de validade negocial no campo laboral. Poucas condutas direcionadas ao bem do outro poder-se-ia esperar do ser humano, que possui altruísmo limitado, recursos limitados e compreensão e força de vontade limitadas. 
A partir do reconhecimento de que o ser humano não é São Francisco de Assis nem egocêntrico insuscetível de se inclinar ao bem de outrem, ganha relevância a ideia de sanção premial que, vista de um ângulo sócio-psicológico, o prêmio transforma o desejo do prêmio motivo da conduta socialmente desejada (KELSEN, 1999, p. 18). Deste modo, o ser humano nunca vai ser aquele hércules ético que fará sempre o bem ao outro pelo bem em si mesmo, sem querer nada em troca, motivo pelo qual Hans Kelsen (1999, p. 18) aduz que o ordenamento eficaz se manifesta quando "a conduta das pessoas corresponde em geral e grosso modo a esse ordenamento, sem ter em conta os motivos pelos quais ela é determinada".

A partir de políticas, torna-se possível criar vantagens/benefícios, por exemplo, para aquelas grandes litigantes que conseguirem diminuir ações perante o Judiciário anualmente ou que possuam um níve ótimo de avaliação dos consumidores e/ou trabalhadores, benefícios que podem variar de desconto em imposto de renda, concessão de certificados de qualidade, vantagens em licitações etecetera. Nesse viés, a responsabilidade civil, fortalecida pelas sanções premiais, surge como um instrumento ético no campo das relações sociais, especialmente porque a amizade mercantil é destituída do elemento presente na amizade plena, visto que ela é limitada ao interesse da troca, sendo assim, mesmo que a práticas sociais denotem para uma suposta inexistência de bens internos plenos no bojo das relações privadas especialmente, surgem as sanções como trunfo para prevenir possívels desvios e primar pelo respeito aos bens humanos básicos e ao bem comum.

\section{CONCLUSÕES}

Conclui-se que a responsabilidade civil está inserida no contexto em que o fenômeno jurídico deve ser expandido para além da dimensão institucional factual (autoritativo e coercitivo) para o fim de incluir como parte do direito uma faceta ética (FINNIS, 2007) ou de correção moral (ALEXY, 2014). É inerente a qualquer sistema jurídico o ideal de promover melhorias no status quo presente no direito institucionalizado e das práticas sociais. Aí está o vínculo entre o direito e a moral: "essa pretensão de correção é a fonte da relação necessária entre o direito e a moral" (ALEXY, 2014, p. 355).

Por conseguinte, a correção moral do direito (ou ética) é realizada na medida em que os bens humanos básicos são atualizados, respeitados, assegurados, protegidos, reparados, compensados, instalando um quadro de maior justiça (dar a cada um o que lhe é devido) de fortalecimento do bem comum (conjunto de condições para que todos possam promover seus projetos de vida). Para isso, contudo, faz-se inarredável o abrandamento da crise ética da responsabilidade civil a partir dos mecanismos expostos na presente pesquisa ou de outros que possam se mostrar adequados ao enfrentamento do declínio ético das relações jurídicas privadas de massa. 


\title{
THE ETHICAL CRISIS OF CIVIL LIABILITY: CHALLENGES AND PERSPECTIVES
}

\begin{abstract}
Develops a concept for civil liability. It reflects on the philosophical foundations of civil responsibility from John Finnis' natural law theory, which is rooted in the Aristotelian-Thomist tradition. It deepens the importance of an ethical dimension in the analysis of civil liability. It demonstrates how the contours of civil liability can cooperate to build a more ethical community. Shows factors that contribute to the current ethical crisis of civil liability. It presents possible perspectives to mitigate this crisis.
\end{abstract}

Keywords: Civil Liability; Mass Damages; Philosophy of Law; Natural Rights; Ethical Crisis

\section{REFERENCIAS}

ALEXY, Robert. Teoria Discursiva do Direito. Trad. Alexandre Travessoni Gomes Trivisonno. 1º ed. Rio de Janeiro: Forense Universitária, 2014.

AZEVEDO, Antonio Junqueira de. Por uma nova categoria de dano na responsabilidade civil: o dano social. In.: Filomeno, José Geraldo Brito; Wagner Júnior, Luiz Guilherme da Costa; Gonçalves, Renato Afonso (Coord.). $O$ Código Civil e sua interdisciplinaridade. Belo Horizonte: Del Rey, 2004.

BARZOTTO, Luis Fernando. Amizade e Mercado: a relação mercantil como pressuposto ético-social dos direitos humanos. Artigo ainda não publicado. 2017.

BONNA, Alexandre Pereira. Punitive Damages (Indenização Punitiva) e os danos em massa. Rio de Janeiro: Lumen Juris, 2015.

CAPPELLETTI, Mauro. Acesso à Justiça. Trad. de Ellen Gracie Northfeet. Porto Alegre: Fabris, 1988.

DIDIER JR, Fredie; CUNHA, Leonardo Carneiro da. Curso de Direito Processual Civil Vol. 3. $13^{\circ}$ ed. Salvador: Editora Juspodiv, 2016.

FINNIS, John. Lei natural e direitos naturais. Trad. Leila Mendes. São Leopoldo: Unisinos, 2007. Stanford Encyclopedia of Philosophy. Natural Law Theories. First published Mon Feb 5, 2007; substantive revision Wed Nov 4, 2015.

Aquinas: Moral, Political, and Legal Theory. Oxford University Press. Londres: 2008.

GASH, Jim. Solving the multiple punishments problem: a call for a national punitive damages registry. Northwestern University Law Review, 2005, vol. 99, n. 4, p. 1613-1686.

GERMANO, Geandrei Stefanelli. Punitive Damages nas relações de consumo. 2011. 167 f. Tese (Mestrado em Direito) - Universidade de São Paulo, São Paulo. 2011.

HART, H. L. A. O Conceito de Direito. Trad. de A. Ribeiro Mendes. Lisboa: Fundação Calouste Gulbenkian, 2007. 
MARTINS-COSTA, Judith; PARGENDLER, Mariana Souza. Usos e abusos da função punitiva: punitive damages e o direito brasileiro. R. CEJ, Brasília, n. 28, p. 15-32, jan./mar. 2005.

Usos e abusos da função punitiva: punitive damages e o direito brasileiro. R. CEJ, Brasília, n. 28, p. 15-32, jan./mar. 2005.

MASSINI-CORREAS, Carlos. Jurisprudencia analítica y derecho natural: análisis del pensamento do filósofojurídico John Finnis. Mendonza-Argentina: 2015.

KELSEN, Hans. Teoria Pura do Direito. Trad. João Baptista Machado. São Paulo: Martins Fontes, 1999.

MCGOVERN, Francis. Punitive damages and class actions. Louisiana Law Review, 2010, vol. 70, p. 435-462.

MACINTYRE, Alasdair. After Virtue. 3a ed. University of Notre Dame Press: Notre Dame, 1981.

PULIDO, Carlos Bernal; ZAMORA, Jorge Fabra. La Filosofia de la Responsabilid Civil: estúdios sobre los fundamentos filosóficos-jurídicos de la responsabilid extracontractual. Bogotá: Universidad Externato ded Colombia, 2013.

SEBOK, Anthony J. Punitive damages: from myth to theory. Iowa Law Review, Vol. 92, 2007.

Trabalho enviado em 19 de julho de 2017.

Aceito em 28 de outubro de 2017. 